\title{
M7: An efficient size-resolved aerosol microphysics module for large-scale aerosol transport models
}

\author{
Elisabetta Vignati and Julian Wilson \\ Institute for Environment and Sustainability, Joint Research Centre, European Commission, Ispra, Italy \\ Philip Stier \\ Max Planck Institute for Meteorology, Hamburg, Germany \\ Received 23 December 2003; revised 21 July 2004; accepted 22 July 2004; published 17 November 2004.
}

[1] An aerosol model (M7) designed to be coupled to general circulation models (GCM) and chemistry transport models (CTM) is described. In M7 the aerosol population is divided into two types of particles: mixed, or water-soluble particles, and insoluble particles. The particles are represented by seven classes, using a "pseudomodal" approach. Four classes are for the mixed particles representing nucleation, Aitken, accumulation, and coarse mode, and three are for the insoluble (Aitken, accumulation, and coarse mode). The components considered are mineral dust, black carbon (BC) and primary organic carbon (OC), sulfate, and sea salt. The aerosol dynamic processes in M7 include nucleation, coagulation, and condensation of sulfuric acid. Mixed particles are formed from insoluble particles by coagulation and condensation. The integration scheme is computationally very efficient. The model has been tested against the analytical solution and a sectional model for the formation of $\mathrm{SO}_{4} / \mathrm{BC}$ mixed particles, evaluating the mixing by condensation and coagulation. Furthermore, M7 has been run in free tropospheric conditions and compared to aircraft observations. M7 has proven to be accurate and fast enough to be included in a GCM or CTM. INDEX TERMS: 0305 Atmospheric Composition and Structure: Aerosols and particles $(0345,4801)$; 0345 Atmospheric Composition and Structure: Pollution-urban and regional (0305); 0368 Atmospheric Composition and Structure: Troposphere - constituent transport and chemistry; KEYWORDS: aerosol particles, pseudomodal algorithm, aerosol dynamics, mixed particles

Citation: Vignati, E., J. Wilson, and P. Stier (2004), M7: An efficient size-resolved aerosol microphysics module for large-scale aerosol transport models, J. Geophys. Res., 109, D22202, doi:10.1029/2003JD004485.

\section{Introduction}

[2] It is accepted that aerosols have a nonnegligible effect on the radiative balance of the Earth's atmosphere [Intergovernmental Panel on Climate Change (IPCC), 2001]. Among the components contributing to this effect, sulfate, sea salt, black carbon (BC), organic carbon (OC) and dust all play an important role, which varies from region to region. Sulfate is hygroscopic and a significant source of cloud condensation nuclei (CCN) [Twomey, 1977; Albrecht, 1989]. Recent studies have shown that sea salt can be found in concentrations comparable to sulfate in the accumulation mode and thus its role as CCN cannot be neglected [O'Dowd et al., 1997]. Hydrophobic particles have a long lifetime in the atmosphere and can be transported further [Cooke and Wilson, 1996]. Chemical reactions may modify $\mathrm{BC}$ and $\mathrm{OC}$ leading to higher solubility and faster removal by wet scavenging.
[3] The aerosol radiative forcing depends on the particle optical properties, which in turn is function of the chemical composition. Most components of aerosol scatter solar radiation, thus cooling the atmosphere in contrast to the warming due to greenhouse gases [Charlson et al., 1991]. On the contrary black carbon strongly absorbs sunlight, potentially warming the atmosphere [Satheesh and Ramanathan, 2000; Eck et al., 1998], while dust and some organic species also absorb [Tegen et al., 1997]. The aerosols have an effect on clouds, changing their albedo, lifetime and precipitation efficiency [Albrecht, 1989; Rosenfeld, 2000; Twomey, 1974]. Water contained in the particles plays a very important role in determining the aerosol optical response, because it is a significant fraction of the aerosol mass. The particle chemical composition controls the amount of water taken up in response to the water vapor content in the air, which governs the ambient particle size. Scattering and absorption by aerosol and the number of particles that can be activated as cloud condensation nuclei are functions of the aerosol composition and size. The confidence in the reliability of estimates of the aerosol radiative effects is "low" in the case of the direct sulfate effect and "very low" for the direct effects 
of fossil fuel derived carbonaceous aerosol, biomass burning aerosol, mineral dust and the indirect effect [IPCC, 2001].

[4] In the past global modeling studies that have calculated radiative effects, have usually assumed an external mixture of the components and constant size distributions [e.g., Haywood and Shine, 1995; Tegen et al., 1997; Takemura et al., 2000], whereas observations [e.g., Bates et al., 1998; Russell et al., 1999; Raes et al., 2000] indicate that in general at some distance from source regions aerosols are internally mixed and the size distributions vary spatially and temporally. The representation of aerosols as internal mixtures in models creates two problems: (1) an aerosol microphysical model is needed to describe the development of the aerosol mixture; (2) the mixtures usually contain compounds of different volatility, and therefore the equilibrium between aerosols and the vapor phase must be calculated. Models have tended to emphasize either one or the other.

[5] Methods used to represent aerosol size distributions have been reviewed in detail by Williams and Loyalka [1991] and Whitby and McMurry [1997]. In recent years several studies have included predictions of explicit size distributions of internal mixtures. Sectional models have been used in multicomponent 3-D studies [e.g., Jacobson, 2001; Gong et al., 2003; Rodriguez and Dabdub, 2004]. Modal models have been employed in regional-scale air quality models [e.g., Ackermann et al., 1998; Schell, 2000] offering computational advantages over the sectional approach. Aerosol dynamics algorithms using sectional and modal approaches in 3-D models have been reviewed by Zhang et al. [1999, 2002]. Both studies have shown that the accuracy of the algorithm is lower when the modal approach is used. Furthermore, when the standard deviation of the modes is not allowed to vary (two-parameter approach) the limitations of the algorithm are even higher. The moment method has been applied in a hemispheric offline transport model [Wright et al., 2001], while a monodisperse aerosol dynamics model has been proposed for inclusion to regional/global models [Pirjola et al., 2003].

[6] Wilson et al. [2001] developed a modal model, M3, to describe internal mixtures of sulfate, black and organic carbon and sea salt and applied in a 3-D global transport model. However in the M3 model black and organic carbon size distributions were fixed, mixing between these components and sulfate was only through condensation, and sea salt was not treated dynamically. Here we have developed the simplified approach of M3 into a generalized model, M7, describing dynamically the evolution of the size distributions of most of the principal components of the global aerosol burden: sulfate, black and primary organic carbon, sea salt and dust. In M7 internally mixed aerosols are produced not only through condensation with sulfuric acid on insoluble particles, but also through coagulation between soluble and insoluble particles.

[7] In the paper the model is presented and an evaluation of the mixing process is described for the system sulfateblack carbon. M7 results are compared to a sectional model for mixing by coagulation and condensation and to an analytical solution for coagulation. Furthermore, M7 has been run in free tropospheric conditions and compared to aircraft observations.

\section{Description}

[8] In our new model, M7, the aerosol population is divided into two externally mixed populations: an internally mixed water-soluble particle population and a population of insoluble particles. The mixed particles are assumed to be a water-soluble mixture of insoluble and soluble material. The separation of the aerosol population into these two populations allows us to represent the evolution of the hygroscopic properties of the initially insoluble compounds, on which their atmospheric lifetimes and also their interaction with clouds depend. If the insoluble compounds were put in the mixed modes when emitted, they would effectively be hygroscopic and they would uptake water increasing the actual radius of the particle and hence be dry deposited more quickly and be activated in clouds and scavenged more efficiently. In the version we describe here the model considers sulfate, black carbon, primary organic carbon, sea salt and mineral dust components. It has however been designed to be able to treat additional components such as nitrate and secondary organic aerosols.

[9] The integration scheme is computationally very efficient. The programming structure allows the optimization for both, vector computers and cache-based computers, depending on the domain decomposition of the host atmospheric model. Embedded in the aerosol model of the ECHAM5 GCM [Roeckner et al., 2003], the M7 microphysical module runs fully vectorized (vector operation ratio $>99 \%$ ) on a 8 CPU NEC SX6 node with an average speed of 3 Gigaflops, contributing $18 \%$ of the total CPU time of the global aerosol-climate model. This allows the usage in long-term transient global climate studies over several centuries in a sufficiently high resolution of horizontally T63 in spectral space, corresponding to $1.8 \times$ 1.8 degrees on a Gaussian grid, and 31 vertical levels.

\subsection{Representation of the Aerosol Size Distribution}

[10] A "pseudomodal" approach is used to describe the particle populations and to calculate the dynamics. The mixed aerosol size distribution is represented by four lognormal modes: nucleation, Aitken, accumulation and coarse, while the rate constants for coagulation and condensation are calculated for the average mode radius rather than the integral over the mode. In this version the nucleation mode contains only sulfate particles, in the Aitken mode black carbon and organic carbon are present in an internal mixture with sulfate, while in the accumulation and coarse modes sea salt and dust may also be present in the mixture. The insoluble aerosols are represented by three lognormal modes: an Aitken mode of internally mixed BC and $\mathrm{OC}$, and accumulation and coarse modes containing dust.

[11] Each mode is represented by the total particle number and mass of each compound. From number and masses the average particle radius is derived. The calculations of particle properties, such as the equilibrium radius, or the coagulation and condensation rates are done based on the average mode radius. The classes are represented by lognormal distributions at the end of the time step, when a 
Table 1. Properties of the Modes of the M7 Model

\begin{tabular}{|c|c|c|c|c|}
\hline Aerosol Modes & $\begin{array}{c}\text { Notation Used in } \\
\text { the Text }\end{array}$ & $\begin{array}{c}\text { Geometric Standard } \\
\text { Deviation } \sigma\end{array}$ & $\begin{array}{l}\text { Dry Radius Size } \\
\text { Interval, } \mu \mathrm{m}\end{array}$ & Prognostic Variables ${ }^{\mathrm{a}}$ \\
\hline 1: Nucleation mode mixed & nuc & $1.59^{\mathrm{b}}$ & $0-0.005$ & $\mathrm{~N} 1, \mathrm{MSO}_{4}(1)$ \\
\hline 2: Aitken mode mixed & ait & $1.59^{\mathrm{b}}$ & $0.005-0.05$ & $\mathrm{~N} 2, \mathrm{MSO}_{4}(2), \operatorname{MBC}(2), \operatorname{MOC}(2)$ \\
\hline 3: Accumulation mode mixed & acc & $1.59^{\mathrm{b}}$ & $0.05-0.5$ & $\mathrm{~N} 3, \mathrm{MSO}_{4}(3), \operatorname{MBC}(3), \operatorname{MOC}(3), \operatorname{MSS}(3), \operatorname{MDU}(3)$ \\
\hline 4: Coarse mode mixed & & 2.0 & $>0.5$ & $\mathrm{~N} 4, \mathrm{MSO}_{4}(4), \mathrm{MBC}(4), \operatorname{MOC}(4), \operatorname{MSS}(4), \operatorname{MDU}(4)$ \\
\hline 5: Aitken mode insoluble & ins & 1.59 & & $\mathrm{~N} 5, \operatorname{MBC}(5), \operatorname{MOC}(5)$ \\
\hline 6: Accumulation mode insoluble & & 1.59 & & N6, MDU(6) \\
\hline 7: Coarse mode insoluble & & 2.0 & & N7, MDU(7) \\
\hline
\end{tabular}

${ }^{\mathrm{a}} \mathrm{N} 1, \ldots, \mathrm{N} 7$ are the particle numbers of mode $1, \ldots, 7 ; \mathrm{MSO}_{4}$ is sulfate mass; MBC is black carbon mass; MOC is organic carbon mass, MSS is sea salt mass; MDU is dust mass (numbers in parenthesis indicate the mode).

${ }^{\mathrm{b}}$ Values are from Wilson et al. [2001].

reallocation of the particles in the modes is done (see section 2.2.2.4). The particle mass is comprised of the 5 components considered by the model, giving together with number and standard deviation a maximum of seven parameters to describe a mode. Hence the complete aerosol size distribution would in principle be described by $7 \times 7=$ 49 tracers. In order to simplify the calculations, we prescribe the geometric standard deviation of each mode and only consider the masses of the components of each mode that can be present (e.g., sulfate for the nucleation mode, dust for the coarse mode insoluble). The total number of tracers thus required is 25 . The size intervals, default standard deviations and mass components that may be present in each mode are given in Table 1.

\subsection{Processes Considered in the Model}

[12] The model M7 has been designed as a general aerosol microphysics module for use in global/regional models. Therefore it considers the processes of nucleation, coagulation and sulfuric acid condensation and water uptake. Intramodal coagulation does not take place for the accumulation insoluble mode and for coarse mixed and insoluble modes. Other relevant processes, such as activation of particles to form cloud droplets, heterogeneous chemistry and scavenging of cloud droplets, and dry deposition, are treated in the large-scale models coupled to M7 and are not described here. We calculate the rate constants for coagulation and condensation as the product of the coefficients for the geometric mean particle radius and the number concentration of the mode, rather than the integral over the mode. The processes considered and the effect they have on the number and mass of each mode are illustrated in Figure 1. In Figure 1 the solid lines correspond to processes influencing the mixed modes, and the broken lines the processes influencing the insoluble modes. The expressions such as $1+1=1,1+2=2$, etc. represent the fate of particles formed by coagulation: a particle in the nucleation mode coagulating with another nucleation mode particle remains in mode 1 , while coagulating with a particle of mode 2 is moved to mode 2 . " $i$ " characterizes the insoluble modes.

\subsubsection{Gas Phase Sulfate Dynamics}

[13] To emulate the sulfur chemistry of the global model, a simplified gas phase sulfur scheme has been implemented, representing the sulfate production by a single production term [Calvert et al., 1978]

$$
\mathrm{SO}_{2}+\mathrm{OH} \rightarrow \mathrm{SO}_{4}^{2-}
$$

Sulfuric acid produced by equation (1) either forms new particles by nucleation, or condenses onto existing aerosols. The change in the sulfuric acid concentration $\left(\mathrm{SO}_{4 g}^{2-}\right)$ is given by:

$$
\frac{d\left\lfloor S O_{4 g}^{2-}\right\rfloor}{d t}=k_{1}[O H]\left[S O_{2}\right]-n_{c} \alpha\left[S O_{4 g}^{2-}\right]^{\beta}-\sum_{i=1,7} N_{i} C_{i}\left[S O_{4 g}^{2-}\right]
$$

where the first term on the right hand side is the sulfate formation rate from equation (1), the second is the loss through nucleation and the final term condensation losses to preexisting aerosol in the seven modes. In 3-D model applications of M7, where operator splitting is used, the first term may be treated by the chemistry scheme and is not therefore included in the equation. In equation (2), $k_{1}$ is the reaction constant $\left(k_{1}=1.1 \times 10^{-12} \mathrm{~cm}^{3}\right.$ molecule $\left.{ }^{-1} \mathrm{~s}^{-1}\right)$, $N_{i}=$ particle number in mode $i, C_{i}=$ condensation coefficient for mode $i, \alpha$ and $\beta=$ nucleation parameters, and $n_{c}=$ critical number of sulfate molecules per nucleation cluster. The condensation coefficient in equation (2) for mode $i$ is determined from Fuchs [1964], using the radius of average surface of mode $i$ :

$$
C_{i}=\frac{4 \pi D \bar{r}_{g i}}{\frac{4 D}{s v \bar{r}_{g i}}+\frac{\bar{r}_{g i}}{\bar{r}_{g i}+\Delta}}
$$

where $\bar{r}_{g i}$ is the geometric mean radius of mode $i, D, v$ and $\Delta$ are respectively the diffusion coefficient, mean thermal velocity and mean free path length of a sulfate molecule and $\mathrm{s}$ is an accommodation coefficient and is taken to be 1.0 for the mixed modes and 0.3 for the insoluble modes [Raes and Van Dingenen, 1992]. The values of the measured accommodation coefficient extend over an interval from 0.03 [Van Dingenen and Raes, 1991] to 1 [Eisele and Tanner, 1993; Jefferson et al., 1997].

[14] The formation of new sulfuric acid-water droplets is described using two parameterizations, one by Kulmala et al. [1998] and one by Vehkamaki et al. [2002], and both are available in the code. The first holds at temperatures between $233 \mathrm{~K}$ and $298 \mathrm{~K}$, and relative humidity between $10 \%$ and $100 \%$. The second parameterization is valid at temperatures between $230.15 \mathrm{~K}$ and $305.15 \mathrm{~K}$ and relative humidity between $0.01 \%$ and $100 \%$. Therefore it is more suitable for the application covering from the boundary 


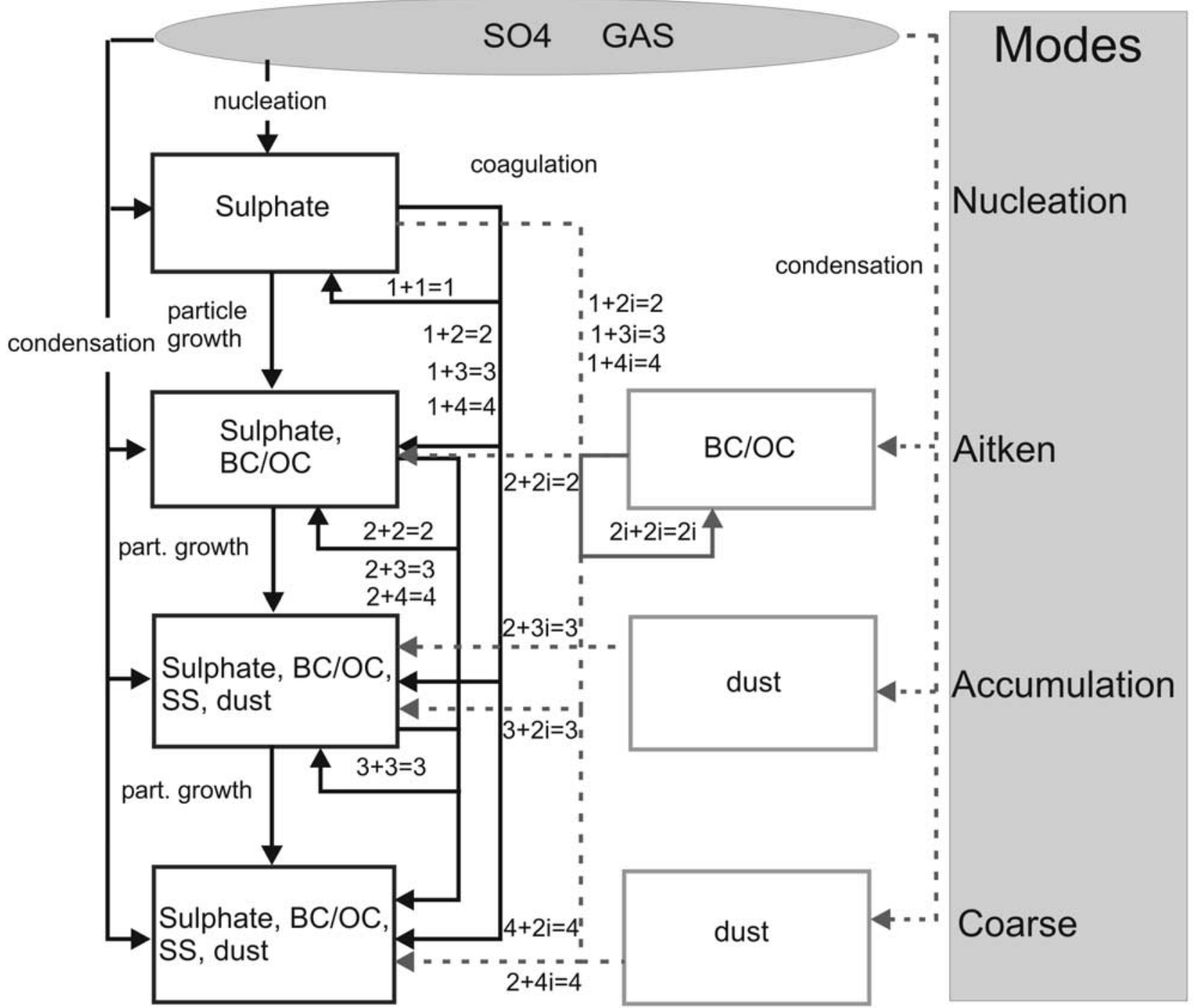

Mixed

Insoluble

Figure 1. Scheme of M7 modes and processes. Solid lines correspond to processes influencing the mixed modes, and dashed lines the processes influencing the insoluble modes. The expressions such as $1+1=1,1+2=2$, etc., represent the fate of particles formed by coagulation: a particle in the nucleation mode coagulating with another nucleation particle remains in mode 1 , while coagulating with a particle of mode 2 forms a particle in mode 2 . Here " $i$ " characterizes the insoluble modes.

layer to the stratosphere and it has been used for the simulations presented in the paper. As with the M3 model we solve equation (2) by splitting it into two parts, to derive analytical solutions to the differential equations for the source and sink processes other than nucleation in the first part and the nucleation term in the second:

$$
\frac{d\left\lfloor S O_{4 g}^{2-}\right\rfloor}{d t}=k_{1}[\mathrm{OH}]\left[S O_{2}\right]-\sum_{i=1,7} N_{i} C_{i}\left[S O_{4 g}^{2-}\right]
$$

$$
\frac{d\left\lfloor S O_{4 g}^{2-}\right\rfloor}{d t}=-n_{c} \alpha\left[S O_{4 g}^{2-}\right]^{\beta}
$$

where the nucleation parameters, $\alpha$ and $\beta$, are obtained from Kulmala et al. [1998] and $n_{c}=100$ [Wilson et al., 2001]. When the Vehkamaki scheme is used, the $\mathrm{H}_{2} \mathrm{SO}_{4}$ gas concentration is assumed constant, equation (4) is integrated over the time step and the resulting final gas phase sulfuric acid concentration used for the initial concentration in the integral of equation (5). 
Table 2. Constant Coefficients of Equation (6)

\begin{tabular}{ll}
\hline Coefficient & \multicolumn{1}{c}{ Value } \\
\hline K1 & 95.80188 \\
K2 & 28.5257 \\
K3 & 1.082153 \\
K4 & 0.1466501 \\
K5 & 20627.51 \\
K6 & 0.0461424 \\
K7 & 0.003935 \\
K8 & 3.36115 \\
K9 & 0.00024137 \\
K10 & 0.0679383 \\
K11 & $6.499 \mathrm{E}-6$ \\
K12 & 8616124.37 \\
K13 & 1.1615558 \\
K14 & 0.02131748 \\
K15 & $7.40534 \mathrm{E}-4$ \\
K16 & 1353332314 \\
K17 & 0.002403805 \\
\hline
\end{tabular}

${ }^{a}$ Read 6.499E-6 as $6.499 \times 10^{-6}$.

\subsubsection{Processes Affecting the Mixed Modes}

\subsubsection{Equilibrium With the Water Vapor}

[15] The particles are assumed to be in equilibrium with water vapor. Only the mixed particles are assumed to be hygroscopic, consequently the equilibrium wet radius is only calculated for particles in the four mixed modes.

[16] For pure sulfate-water particles new parameterizations for water uptake including the Kelvin effect, and particle density $(\rho)$ have been developed. They are based on regression fits to solutions of the generalized Kelvin equation [Zeleznik, 1991] for temperatures between 240$330 \mathrm{~K}$, relative humidity between 0.10 and $95 \%$, pressures between 50 and $1050 \mathrm{hPa}$ and sulfate masses between $10^{2}$ and $10^{12}$ molecules:

$$
\begin{aligned}
\overline{W_{S O_{4}, j}} & =K_{1}-K_{2} \ln \left(\overline{n S O_{4, j}}\right)-K_{3} S \ln \left(\overline{n S O_{4, j}}\right)+K_{4} T \ln \left(\overline{n S O_{4, j}}\right) \\
& -K_{5} \frac{S}{T}+K_{6} S\left[\ln \left(\overline{n S O_{4, j}}\right)\right]^{2}-K_{7} T\left[\ln \left(\overline{n S O_{4, j}}\right)\right]^{2} \\
& -K_{8} S^{2} \ln \left(\overline{n S O_{4, j}}\right)-K_{9} T^{2} \ln \left(\overline{n S O_{4, j}}\right)+K_{10} S^{2}\left[\ln \left(\overline{n S O_{4, j}}\right)\right]^{2} \\
& +K_{11} T^{2}\left[\ln \left(\overline{n S O_{4, j}}\right)\right]^{2}+K_{12} \frac{S^{2}}{T^{2}}+K_{13}\left[\ln \left(\overline{n S O_{4, j}}\right)\right]^{2} \\
& -K_{14}\left[\ln \left(\overline{n S O_{4, j}}\right)\right]^{3}+K_{15}\left[\ln \left(\overline{n S O_{4, j}}\right)\right]^{4}-K_{16} \frac{S^{3}}{T^{3}} \\
& -K_{17} n\left(\frac{S^{*} T}{P}\right) \\
\rho= & H_{1}+H_{2} \overline{W_{S O_{4, j}}}-H_{3} \ln \left(\overline{n S O_{4, j}}\right)-H_{4} S+H_{5} T \\
+ & H_{6}\left[\ln \left(\overline{n S O_{4, j}}\right)\right]^{2}+H_{7}-H_{8} \frac{\ln \left(\overline{n S O_{4, j}}\right)}{T}-H_{9} T^{2}
\end{aligned}
$$

where $S$ is the relative humidity $(0-1), T$ the absolute temperature, $P$ the pressure in Pascal, $\overline{n S O_{4, j}}$ the number of sulfate molecules in a particle of average mass for mode $\mathrm{j}$, and $\overline{W_{S O_{4}, j}}$ the percentage $\mathrm{SO}_{4}$ content by volume of the particle. The constant coefficients $\mathrm{K}_{\mathrm{p}_{2}}$ and $\mathrm{H}_{\mathrm{q}}$ are given in Tables 2 and 3 , respectively. The $\mathrm{R}^{2}$ coefficients for the regression between the new parameterization and the solutions are 0.997 for the percentage $\mathrm{SO}_{4}$ content by volume and 0.992 for the particle density. The parameterizations have the advantage of not requiring an iterative solution. The comparison with the full scheme from
Zeleznik [1991] has been done for temperature and relative humidity ranges where the full scheme is valid. The parameterizations overestimate the water uptake: they predict a larger particle radius from a few percent up to $24 \%$ compared to the full scheme; the larger differences are at low temperature and high relative humidity limits of the parameterization.

[17] For the mixed Aitken and accumulation particles a similar approach is used when both soluble and insoluble compounds are present. BC, $\mathrm{OC}$ or dust are not assumed to influence the water uptake and the effective soluble mass is used to calculate the equilibrium density from equations (6) and (7) and from this the total volume and radius of a spherical mixed particle. It must be mentioned that organic carbon may change the hygroscopic properties of inorganic aerosols [Hansson et al., 1990; Virkkula et al., 1999; Tervahattu et al., 2002; Decesari et al., 2003], If sea salt is present in either the accumulation or coarse mode, then total ion dissociation is assumed. The ZSR method [Zdanovskii, 1948; Stokes and Robinson, 1966] is used to calculate the amount of water attached to the particle as well as parameters from Jacobson et al. [1996] for the calculation of molalities. At relative humidity larger than $45 \%$ the salts are considered dissolved. This value corresponds to the crystallization point for $\mathrm{NaCl}$. In fact particles generated from the sea surface undergo evaporation, and below the deliquescence point $(75.3 \%$ for $\mathrm{NaCl})$ they are in a supersaturated state, and become dry only when relative humidity decreases below 42\% [Shaw and Rood, 1990].

[18] This scheme was compared to AIM (aerosol inorganics model) [Carslaw et al., 1995; Clegg et al., 1998a, 1998b], which calculates the thermodynamic properties of aerosol inorganic constituents (AIM can be run at the European AIM server at http://www.uea.ac.uk) for the system nitrate/sodium/sulfate/nitrate/chloride/water at $298.15 \mathrm{~K}$. The testing was made on the amount of liquid water for various $\mathrm{SO}_{4}, \mathrm{Na}$ and $\mathrm{Cl}$ concentrations. For relative humidity above $75 \% \mathrm{M} 7$ predicts somewhat less uptake of water (up to $12 \%$ ). For relative humidity between 45 and $75 \%$ the overestimation of M7 is around $1-3$ orders of magnitude due to the fact that the salts are assumed to be fully dissociated and there is no formation of solids, whereas in reality particles are in a metastable state.

\subsubsection{Condensation}

[19] Gaseous sulfuric acid condenses on all aerosol modes. The change in the sulfate mass (molecules $\mathrm{cm}^{-3}$ ) of the nucleation mode is given by:

$$
\frac{d\left\lfloor S O_{4,1}\right\rfloor}{d t}=\frac{N_{1} C_{1}}{\sum_{i=1,7} N_{i} C_{i}}\left(\sum_{i=1,7} N_{i} C_{i}\left[S O_{4 g}^{2-}\right]\right)
$$

Table 3. Constant Coefficients of Equation (7)

\begin{tabular}{cl}
\hline Coefficient & \multicolumn{1}{c}{ Value } \\
\hline H1 & 1.036391467 \\
H2 & 0.0072853 \\
H3 & 0.003671296 \\
H4 & 0.06888741 \\
H5 & 0.001047842 \\
H6 & 0.0001116623 \\
H7 & 0.00024683447 \\
H8 & 0.360400895 \\
H9 & $2.9113 \mathrm{E}-6$ \\
\hline
\end{tabular}


where $\sum_{i=1,7} N_{i} C_{i}\left\lfloor S O_{4 g}^{2-}\right\rfloor$ is the total condensation term from equation (4). For the other mixed modes $(j=2,4)$, in addition to the direct condensation of sulfate, there is an additional indirect source namely the sulfate that has condensed onto the corresponding insoluble mode, transferring particles to the mixed mode.

$$
\frac{d\left\lfloor S O_{4, j}\right\rfloor}{d t}=\frac{N_{j} C_{j}+N_{j+3} C_{j+3}}{\sum_{i=1,7} N_{i} C_{i}}\left(\sum_{i=1,7} N_{i} C_{i}\left[S O_{4 g}^{2-}\right]\right)
$$

The above equations are solved for each time step using analytical solutions.

\subsubsection{Changes in Number Concentrations Due to Nucleation and Coagulation}

[20] Coagulation rates are a function of both the particle number concentrations and particle size. Consequently, at typical ambient concentrations, the characteristic timescales for intermodal and intramodal coagulation of insoluble accumulation mode and all coarse mode coagulation are sufficiently long (several days) for these processes to be ignored in global modeling applications of M7.

[21] The change in the number concentration of the nucleation mode particles is given by:

$$
\frac{d N_{1}}{d t}=-\frac{1}{2} K_{11} N_{1}^{2}-\sum_{j=2,7} K_{1, j} N_{j} N_{1}+S_{1}
$$

where $K_{11}$ is the intramodal coagulation coefficient for nucleation mode aerosol and $K_{1 j}$ the intermodal coagulation coefficient for coagulation between the nucleation mode and mode $j$. The intramodal and intermodal coagulation coefficients are determined from Fuchs [1964] as

$$
K_{i j}=\frac{16 \pi \bar{D} \bar{r}}{\frac{4 \bar{D}}{\overline{v r}}+\frac{\bar{r}}{\bar{r}+\Delta^{\prime}}}
$$

where $\bar{D}, \bar{v}$ and $\Delta^{\prime}$ are respectively the diffusion coefficient, thermal velocity, and mean free path length for an aerosol with radius $\bar{r}=\frac{\bar{r}_{g i}+\bar{r}_{g j}}{2}$, the mean of the geometric mean radii of the modes $i$ and $j$.

[22] The analytical integral of equation (4) gives the gas phase sulfuric acid concentration that nucleates in a time step. Dividing this by the critical nucleation cluster $n_{c}$ gives the number concentration of new clusters nucleating in a time step, and further dividing this by the time step gives the nucleation mode particles source rate $S_{1}$. Not all the sulfuric acid nucleates, a part remains in the gas phase.

[23] Intermodal coagulation is considered for the mixed Aitken mode and intramodal coagulation is considered for the mixed accumulation mode:

$$
\begin{gathered}
\frac{d N_{2}}{d t}=-\frac{1}{2} K_{22} N_{2}^{2}-\sum_{j=3,4,6,7} K_{2, j} N_{2} N_{j} \\
\frac{d N_{3}}{d t}=-\frac{1}{2} K_{33} N_{3}^{2}
\end{gathered}
$$

M7 uses analytical integrals of equations (10), (12), and (13) to calculate the changes in the numbers in each mode for the model time step.

[24] The changes in mass concentration due to nucleation and coagulation are calculated as follows. A newly nucleated particle adds a dry mass to the nucleation mode corresponding to the number of molecules in the critical cluster. A particle resulting from intramodal coagulation remains in that mode so that the total mass concentration of the mode remains unchanged, but as the number of particles decreases the average particle mass increases. For intermodal coagulation, when a particle from mode $i$ coagulates with a particle of mode $j$, the average dry mass of mode $i$ is transferred to mode $j$. The transfer of number and mass is consistent so that the average mass of mode $i$ is unchanged, while that of mode $j$, increases.

\subsubsection{Reallocation of Aerosol Number and Mass of the Mixed Modes}

[25] Condensation and coagulation increase the geometric mean radii of the mixed modes and the smaller modes will grow into the size domain of the larger ones. This is not a problem in a box model, which looks at a 'closed' parcel of air, as long as there are not any newly nucleated particles added to a preexisting 'nucleation mode' that has grown into the Aitken mode size range. In 3-D transport model applications the number and masses of the modes are transported tracers and must therefore be 'equivalent' from one grid element to the next. As the modes are defined by size intervals, M7 constrains the modes, by transferring particles that have a larger radius than the upper limit to the next mode, so that the same modes in adjacent grid elements will occupy the same size intervals.

[26] The transfer procedure is applied to the mixed modes. Each mode has a defined size domain and particles need to be transferred from one mode to the adjacent larger one when they grow. This is numerically diffusive, consequently the dimensions of the mixed modes are only allowed to vary within fixed size intervals and upper thresholds of the modes are set to keep the modes separated $\left(r_{\text {div }}\right)$ (see Table 1). The modes are assumed to follow lognormal size distributions, enabling the number and mass concentrations of the fraction of the mode larger than the threshold radius for transfer into the next mode $\left(\bar{N}_{\text {trans }}\right.$, $\left.\bar{M}_{\text {trans }}\right)$ to be calculated [Wilson et al., 2001].

[27] However transferring number and mass larger than the threshold radius $r_{d i v}$, reduces the radius of the residual particles in the mode, which is physically unrealistic. This effect is minimized transferring mass and number only if the average mass contained in the mode is greater than the average mass $\left(\mathrm{m}_{\text {ave }}\right)$ for a particle of radius $\left(e^{\left[\frac{\ln \left(r_{d i v}, j-1\right)+\ln \left(r_{d i v}\right)}{2}\right]}\right)$. If this condition is satisfied all particles larger than the threshold radius are transferred together with their corresponding mass, and the remaining average mass is not smaller than $\mathrm{m}_{\text {ave }}$. In this way $\bar{N}_{\text {trans }}$ and $\bar{M}_{\text {trans }}$ are reduced and the average radius of the remaining particles is not allowed to shrink below the median radius of the mode boundaries.

\subsubsection{Processes Affecting the Insoluble Modes}

[28] Coagulation and condensation are the two processes affecting the insoluble modes. Intramodal coagulation takes place only for particles in mode 5. Accumulation and coarse insoluble modes contain only dust. It is assumed that the 
sticking coefficient for dust is so small that pure dust particles do not coagulate to each other.

[29] The change in number concentration of the insoluble Aitken mode particles $\left(\mathrm{N}_{5}\right)$, is due to intramodal coagulation and intermodal coagulation and described by

$$
\frac{d N_{5}}{d t}=-\frac{1}{2} K_{55} N_{5}^{2}-\sum_{j=2-4} K_{5, j} N_{j} N_{5}
$$

The variation of number concentrations in accumulation $\left(\mathrm{N}_{6}\right)$ and coarse $\left(\mathrm{N}_{7}\right)$ mode is only due to intermodal coagulation.

[30] When an insoluble particle has enough soluble material associated with it to be moved to the mixed modes it is defined as "aged". The ageing of insoluble particles is assumed to be due to the combined condensation of soluble gases, in this version sulfuric acid, and coagulation of soluble component (sulfate in this version) with insoluble particles.

[31] When coagulation takes place between insoluble particles and soluble particles of much smaller size (for instance, between modes 5 and 1, or between 6 and 1 or 2 ) there may not be enough soluble material to form mixed particles. In this case the mass of insoluble mode $j$ aged in a time step is calculated from the sum of the gas phase sulfuric acid condensing on the mode (9) and coagulation of soluble mode sulfate onto the mode:

$$
\frac{d\left[M_{j}\right]}{d t}=-\frac{\frac{N_{j} C_{j}}{\sum_{i=1,7} N_{i} C_{i}} \sum_{i=1,7} N_{i} C_{i}\left[S O_{4}^{g}\right]+\sum_{l=1, n} K_{l, j} N_{l} N_{j} \overline{S O_{4, l}}}{S O_{4, a j}} \overline{M_{j}}
$$

where $\mathrm{SO}_{4, a j}$ is the mass of sulfate required to age an average insoluble particle of mode $\mathrm{j}(\mathrm{j}=5,6,7), \overline{\mathrm{SO}_{4, l}}$ the average mass a of particle of mode $l$, and $\bar{M}_{j}$ the average mass of particles in mode $\mathrm{j}$. The index $\mathrm{n}$ in the expression $\sum_{l=1, n} K_{l, j} N_{l} N_{j} \overline{S O_{4, l}}$ can be 1 or 2 . For particles transferred from mode 5 only intermodal coagulation between modes 5 and 1 is taken into account and $\mathrm{n}$ is equal to 1 . For modes 6 and 7 coagulation with mode 2 is also considered and $\mathrm{n}$ is 2 . From the available sulfate mass and the chosen value for $\mathrm{SO}_{4, a j}$ the number of mixed particles which are formed are calculated. A preliminary test has been made checking the results of equation (15) for coagulation of insoluble particles with smaller soluble particles. The time evolutions of the soluble, insoluble, mixed and total particle populations have been compared to the analytical solution of the time evolution equations for a population of soluble and insoluble particles of uniform dimensions [Smoluchovski, 1917; Fassi-Fihri et al., 1997]. The mechanism for coagulation in equation (15) gives a significantly lower formation rate for mixed particles than the analytical solution, while the total particle losses due to coagulation are accurately calculated by M7. We therefore calculate the equivalent analytical solution to equation (14), and use this to redistribute intermodal and intramodal coagulations, in order to approximate to the analytical solution for the number of mixed particles formed. In this way the formation of mixed particles is "forced" to represent results closer to the analytical solution even though the results are not the same, as we can see in the next section.

[32] The following section contains simulations of $\mathrm{M} 7$ with the assumption that $\mathrm{SO}_{4, a j}$ correspond to a monolayer of sulfate. Sensitivity studies on the behavior of the model as function of the choice of $\mathrm{SO}_{4, a j}$ are reported in the section 3.1.3.

\section{Simulations and Tests}

\subsection{Comparison With a Sectional Model}

[33] M7 has been tested against the sectional model AERO3 (see Vignati [1999] and Raes et al. [2000] for a more extensive description). AERO3 is a box model and simulates the aerosol dynamics of three particle populations: $\mathrm{H}_{2} \mathrm{SO}_{4}-\mathrm{H}_{2} \mathrm{O}$ droplets, $\mathrm{BC}$, and mixed $\mathrm{H}_{2} \mathrm{SO}_{4}-\mathrm{H}_{2} \mathrm{O}-\mathrm{BC}$ particles. The $\mathrm{H}_{2} \mathrm{SO}_{4}-\mathrm{H}_{2} \mathrm{O}$ and $\mathrm{BC}$ particles are assumed to be spheres. Their geometrical radius is discretized in 46 classes corresponding to a range from $0.001 \mu \mathrm{m}$ to $31.6 \mu \mathrm{m}$, using $r_{n}=0.001 \times 10^{(n / 10)}$, where $\mathrm{n}=0$ to 45 . The mixed particles are assumed to consist of an insoluble (BC) core surrounded by a soluble $\left(\mathrm{H}_{2} \mathrm{SO}_{4}-\mathrm{H}_{2} \mathrm{O}\right)$ shell. Their size is discretized into $46 \times 46$ classes, one dimension for the particle size and one dimension for the size of the insoluble core. A mixed particle is formed from an insoluble core of radius $r_{i}$ when due to coagulation or/and condensation there is enough soluble material to form a particle having a radius $r_{p}$ with $\mathrm{p}>\mathrm{i}$. The criteria by which $r_{n}$ is discretized determines how much soluble material should be in a mixed particle.

[34] The model allows for the internal mixing of the particles by coagulation, condensation, nucleation and in-cloud $\mathrm{SO}_{2}$ oxidation. The nucleation of $\mathrm{H}_{2} \mathrm{SO}_{4}-\mathrm{H}_{2} \mathrm{O}$ droplets is treated using the Kulmala et al. [1998] parameterization of the homogeneous nucleation rates, one of the options of M7. For condensational growth both kinetic and continuum regimes are considered [Fuchs, 1964].

[35] The evolution of particle number concentration is described by a system of coupled nonlinear equations, one equation for each class. The system of equations is solved using the Euler Backward Iterative method.

[36] Tests have been designed to evaluate the M7 treatment of the mixed particle production by coagulation and condensation of sulfuric acid compared to AERO3. For these tests the integration time in M7 has been set to $30 \mathrm{~min}$, corresponding to a typical GCM time step at T42 $\left(2.8^{\circ} \times\right.$ $2.8^{\circ}$ ) resolution. AERO3 runs with a time step of $150 \mathrm{~s}$.

\subsubsection{Coagulation}

[37] In the first test $\mathrm{M} 7$ and $\mathrm{AERO} 3$ were initialized with $10^{4} \mathrm{BC}$ particle $\mathrm{cm}^{-3}$ in the Aitken insoluble mode (average radius is $0.0085 \mu \mathrm{m}$ ) and $10^{6}$ sulfate particles $\mathrm{cm}^{-3}$ in the nucleation mode to test the formation of mixed particles by intermodal coagulation, between soluble and insoluble modes. Particles were left coagulating for 24 hours and the evolution of the total particle and $\mathrm{BC}$ particle numbers are compared (Figure 2) also to the analytical solution. To compare with the analytical solution it is necessary to fix the coagulation coefficient, which must be independent of the particle size and it has been set to $2 \times 10^{-9} \mathrm{~cm}^{-3} \mathrm{~s}^{-1}$.

[38] Both models and the analytical solution predict the same evolution of the total particle numbers with time. M7 does however, transfer particles to the mixed mode more 


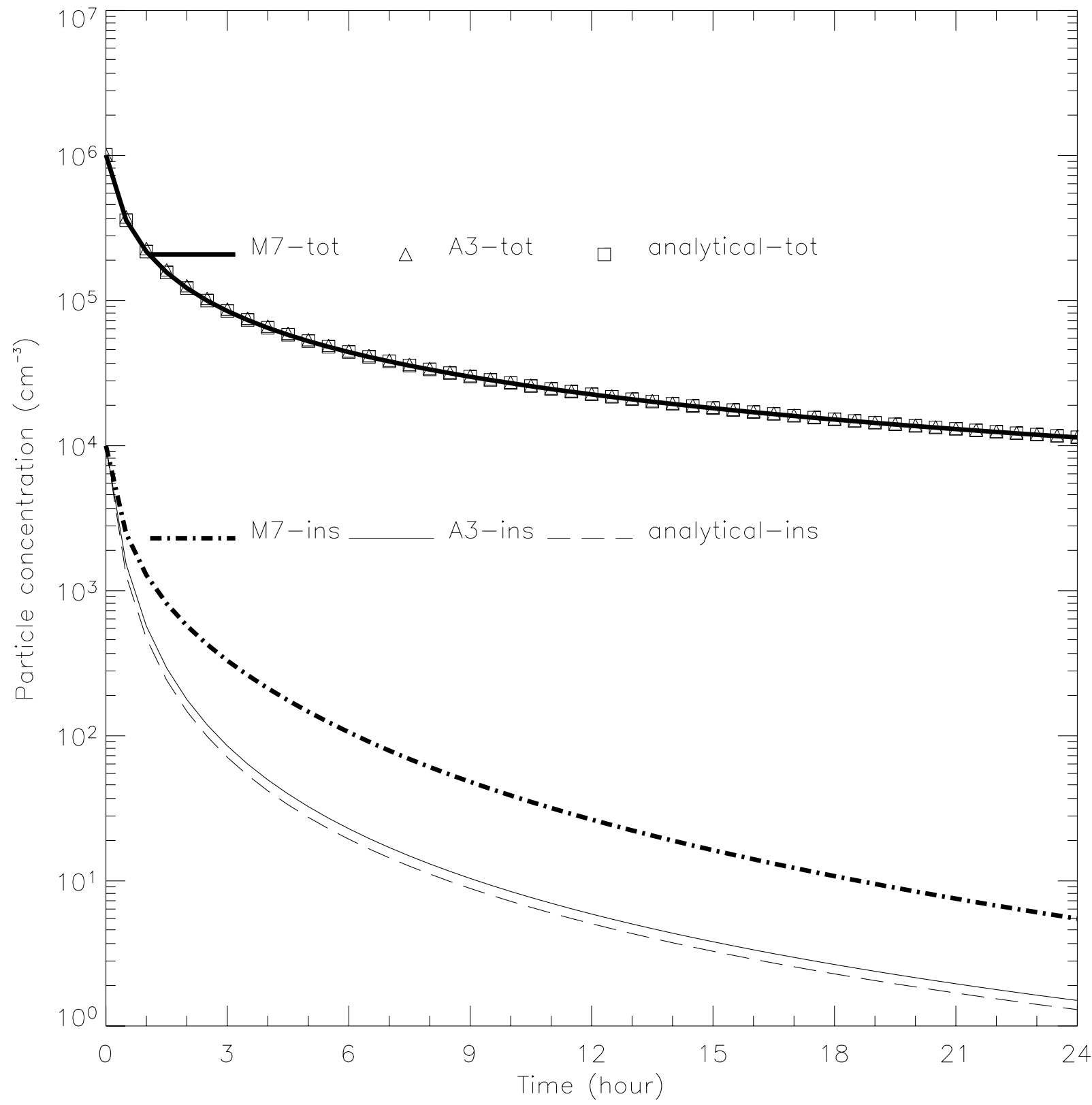

Figure 2. Results of M7 for coagulation: Comparison with the analytical solution and AERO3.

slowly than do the analytical solution and AERO3. The differences between the two models are apparent after the first hour where the residual concentration of insoluble particles is within $10 \%$ of the initial concentration. In the first hour the three approaches are effectively identical. Afterward, the difference increases with time for the first three hours when the remaining insoluble particle concentration is 4 times higher in M7. After that no increasing difference is noticeable. This discrepancy may be due to AERO3 being able to resolve the size distribution more finely than $\mathrm{M} 7$, and also having more efficient coagulation algorithm, with results very similar to the concentrations given by the analytical solution.

[39] A more realistic test is shown in Figure 3. The evolution of the AERO3 size distributions and the radius of the nucleation (M7-nuc), Aitken mixed (M7-ait) and insoluble (M7-ins) of M7 during a 24 hour simulation with a coagulation coefficient dependent on the particle dimension are depicted. The colored contour plot in Figure 3a corresponds to the particle size distribution of AERO3, and the black lines to the M7 mode radii. The M7 nucleation and Aitken insoluble mode radii follow closely the evolution of AERO3 size distribution. The line of the insoluble Aitken mode radius disappears in Figure 3a when the particle concentration of the mode has decreased below $1 \%$ of the initial concentration, due to the transfer into the mixed mode. In M7 the Aitken mixed mode appears soon after the simulation starts due to the transfer mechanism explained in section 2.2.2.4. While in AERO3 the fine size resolution allows for a smooth transition of particle along the size distribution, the discrete nature of the modes in M7 and the way the particles are reallocated 


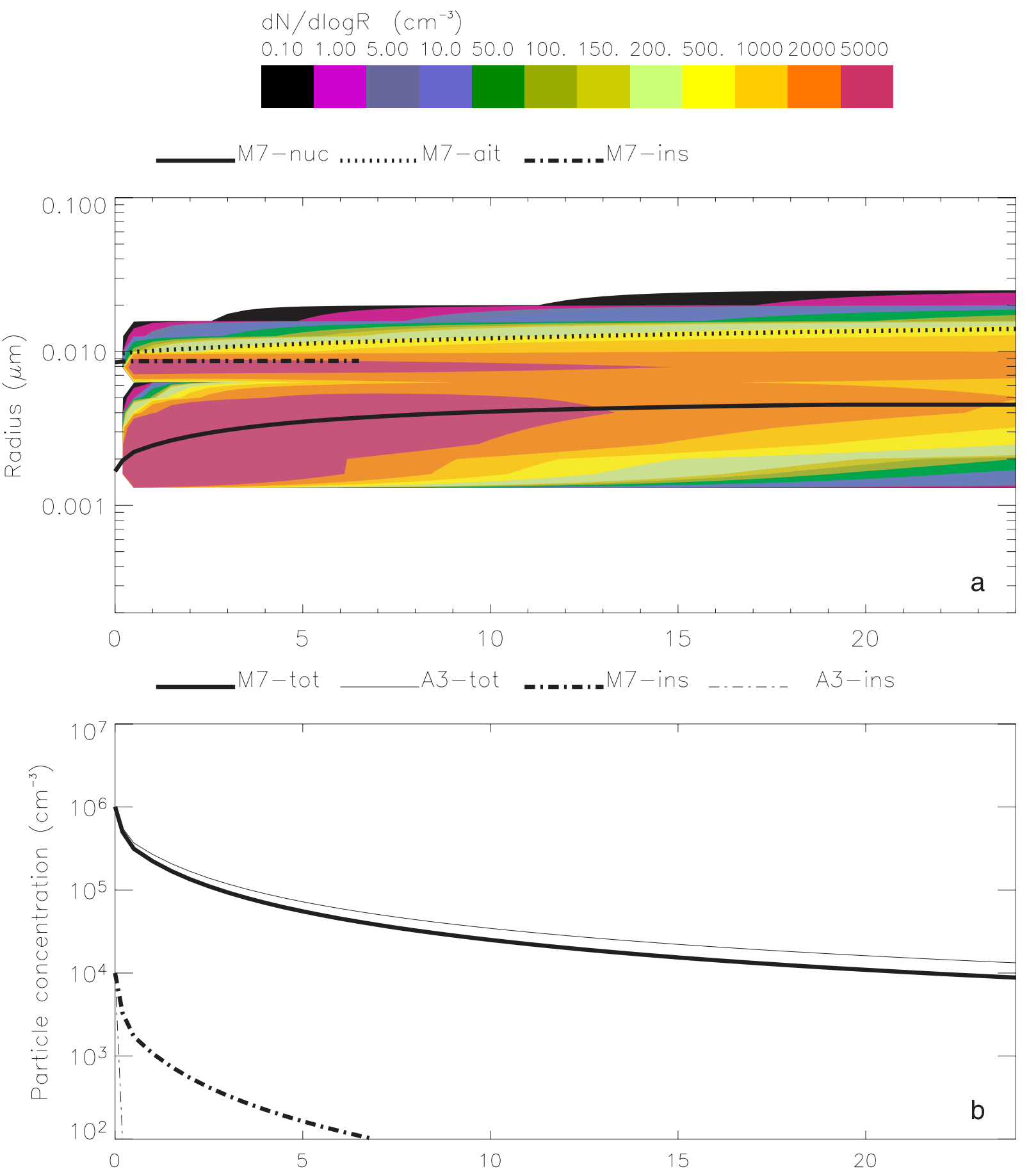

Figure 3. Comparison of $\mathrm{M} 7$ and AERO3: Coagulation between $\mathrm{BC}$ and sulfate particles. (a) Evolution of the size distribution form AERO3 (colored surface) and radius of M7 modes (lines); (b) total particle and insoluble number concentrations. The line of the Aitken mode radius disappears when the particle concentration of the mode has decreased below $1 \%$ of the initial concentration.

may cause a "jump" of particles between the modes, resulting in the formation of the adjacent mode. Therefore after 24 hours the AERO3 size distribution has two modes very close to each other, while in M7 the two modes are farther apart. The appearance of the larger Aitken mode favors coagulation (the more different the coagulating particle radii are the more efficient the mechanism is) and this explain the faster decrease of the total particle number in Figure 3b.

\subsubsection{Condensation}

[40] The formation of mixed particles by condensation with sulfuric acid is studied in a second test. The initial distribution contains the same initial population of $10^{4} \mathrm{~cm}^{-3}$ insoluble particles, and initial $\mathrm{SO}_{2}$ concentration is $0.5 \mathrm{ppb}$. 

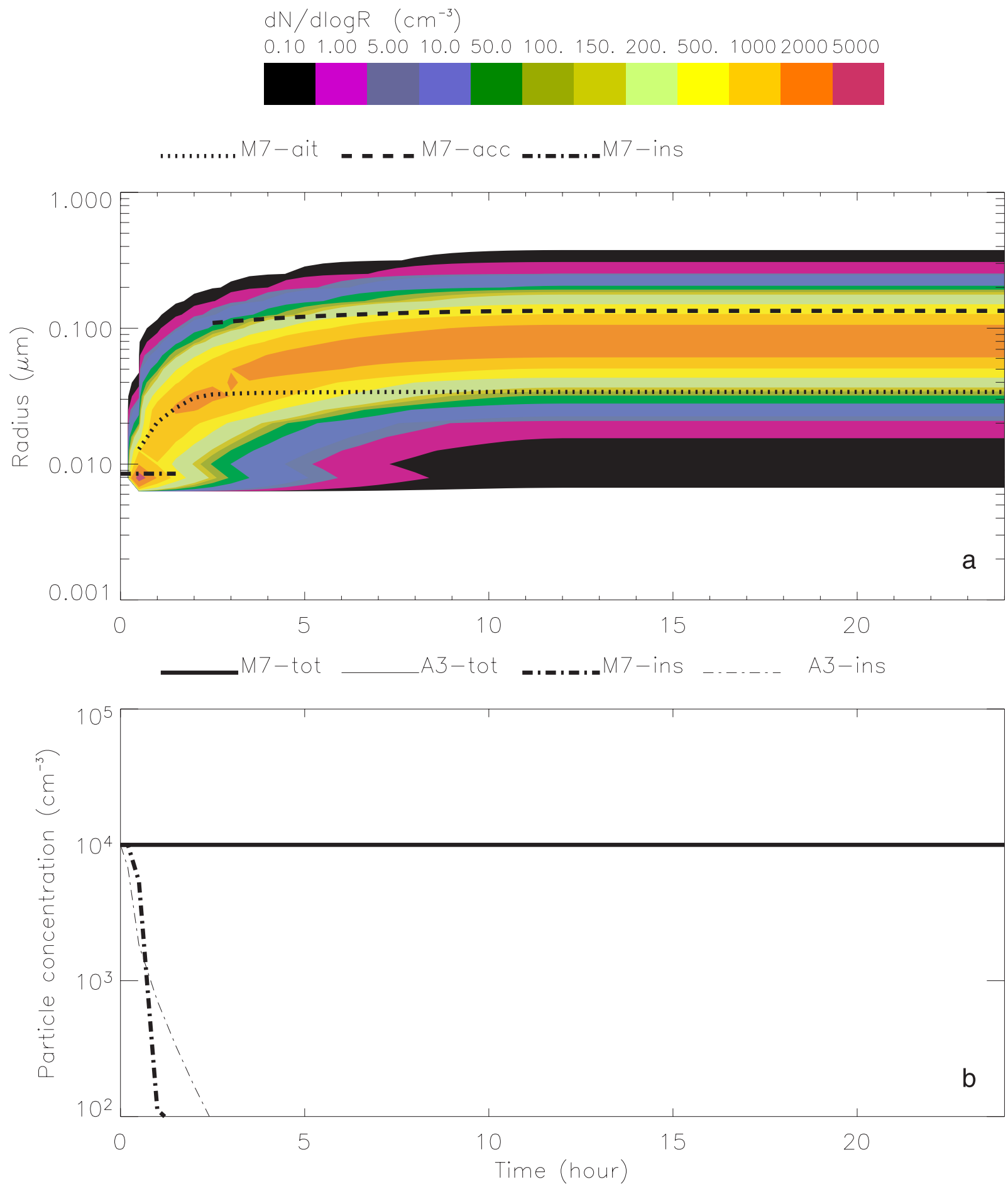

Figure 4. Comparison of $\mathrm{M} 7$ and AERO3: Condensation of sulfuric acid on $\mathrm{BC}$ particles. (a) Evolution of the size distribution form AERO3 (colored surface) and radius of M7 modes (lines); (b) total particle and insoluble number concentrations. M7 was run assuming 1 layer of sulfate to form mixed particles. The line of the Aitken mode radius disappears when the particle concentration of the mode has decreased below $1 \%$ of the initial concentration. 
$\mathrm{dN} / \mathrm{dlog} R\left(\mathrm{~cm}^{-3}\right)$

0.101 .005 .0010 .050 .0100 .150 .200 .500 .100020005000
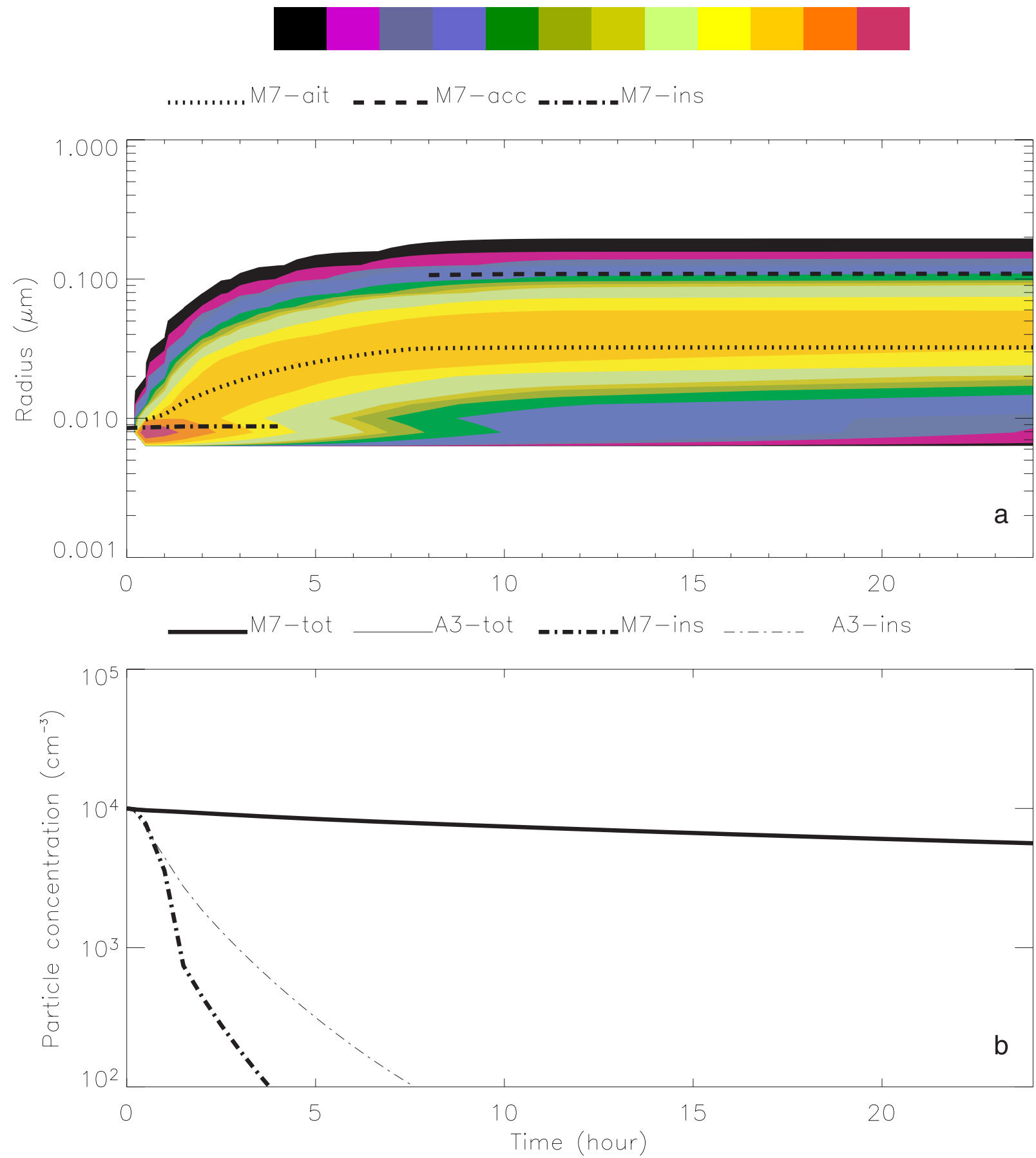

Figure 5. Comparison of $\mathrm{M} 7$ and AERO3: Coagulation and condensation of sulfuric acid on $\mathrm{BC}$ particles. (a) Evolution of the size distribution form AERO3 (colored surface) and radius of M7 modes (lines); (b) total particle and insoluble number concentrations. The line of the Aitken mode radius disappears when the particle concentration of the mode has decreased below $1 \%$ of the initial concentration. 


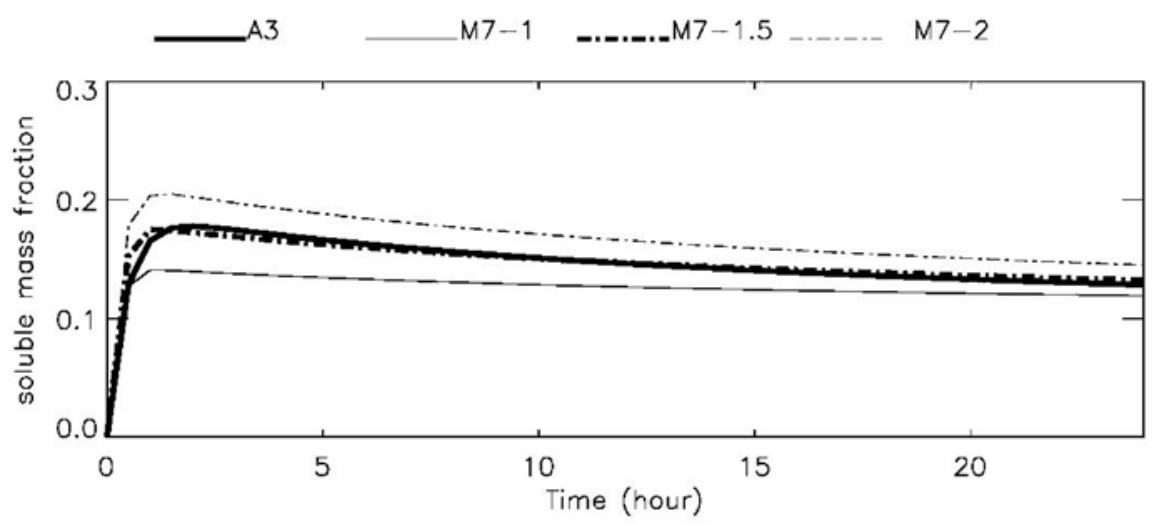

a)

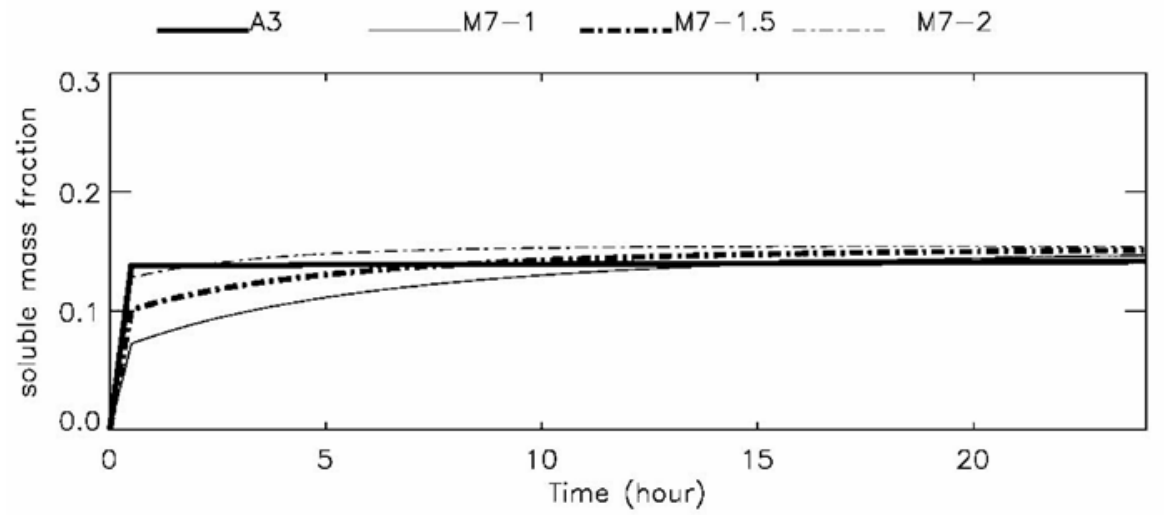

b)

Figure 6. Comparison of M7 and AERO3: Soluble mass fraction of the mixed Aitken mode. (a) Coagulation between BC and sulfate particles; (b) coagulation and condensation of sulfuric acid on BC particles. M7 was run assuming 1, 1.5, and 2 layers of sulfate to form mixed particles.

The transfer of the insoluble particles to the mixed Aitken mode is faster in M7 compared to AERO3. The evolution of the M7 insoluble and soluble Aitken radii follows the bimodal distribution of AERO3 for the first 3 hours (Figure 4a). Afterward, the accumulation mode appears in M7 and after 24 hours the unimodal distribution of AERO3 peaks between the two M7 final modes, although it should be noted that the M7 size distribution is the sum of all the modes, so inevitably a monomodal distribution will be divided across two modes by M7. Another test has been done with the same initial conditions allowing condensation and coagulation as well and is shown in Figure 5. The total particle numbers are the same at any time (Figure 5b) while the transfer of the insoluble particle to the mixed phase in M7 is faster than in AERO3.

\subsubsection{Sensitivity of the Soluble Mass Fraction to the} Aging Assumption

[41] The soluble mass fraction $(\epsilon)$ is important because the activation of a particle in a cloud depends on its size and soluble mass content. The mass of sulfate required to age an average insoluble particle $\left(\mathrm{SO}_{4, \text { aj }}\right)$ in equation (15) depends on the particle dimension and it is an arbitrary parameter. The more sulfate is necessary to move each particle to the mixed modes the higher is the number of insoluble particles remaining in the original mode. This choice influences also the soluble mass fraction of the mixed particles. The cases presented in Figures 3 and 5 were repeated with the hypothesis that $1,1.5$, and 2 sulfate layers are necessary to form a new mixed particle (Figure 6). In AERO3 the soluble fraction is calculated as an average over the entire mixed population. In M7 the soluble fraction is that of the mixed Aitken mode. In this mode not only the mass and number of the new mixed particles are transferred but also the particles in the nucleation mode which have grown enough to be moved to the Aitken mode.

[42] The sulfate mass coming from the nucleation mode is an additional increase of the mass in the Aitken mode compared to the transfer of the sulfate carried by the insoluble particles moved to the mixed mode. In fact while in AERO3 the soluble fraction (Figure 6a) is increasing slightly, in M7 it increases for most of the time, due to nucleation mode particle growth, until an asymptotic value is reached. At the beginning of the simulation the choice of the layering matters, afterward the difference becomes small.

[43] In the second case (condensation of sulfuric acid on $\mathrm{BC}$ particles and coagulation) the behavior of the two models is very similar. The choice of 1.5 layers seems to describe better the soluble mass content of the mixed particles for this case in comparison with AERO3.

\subsection{Simulation of Aerosol Dynamics in the Free Troposphere}

[44] Much of aerosol size distributions in the boundary layer is determine by primary emissions, especially in vicinity of urban/industrial centers, while in the free tropo- 


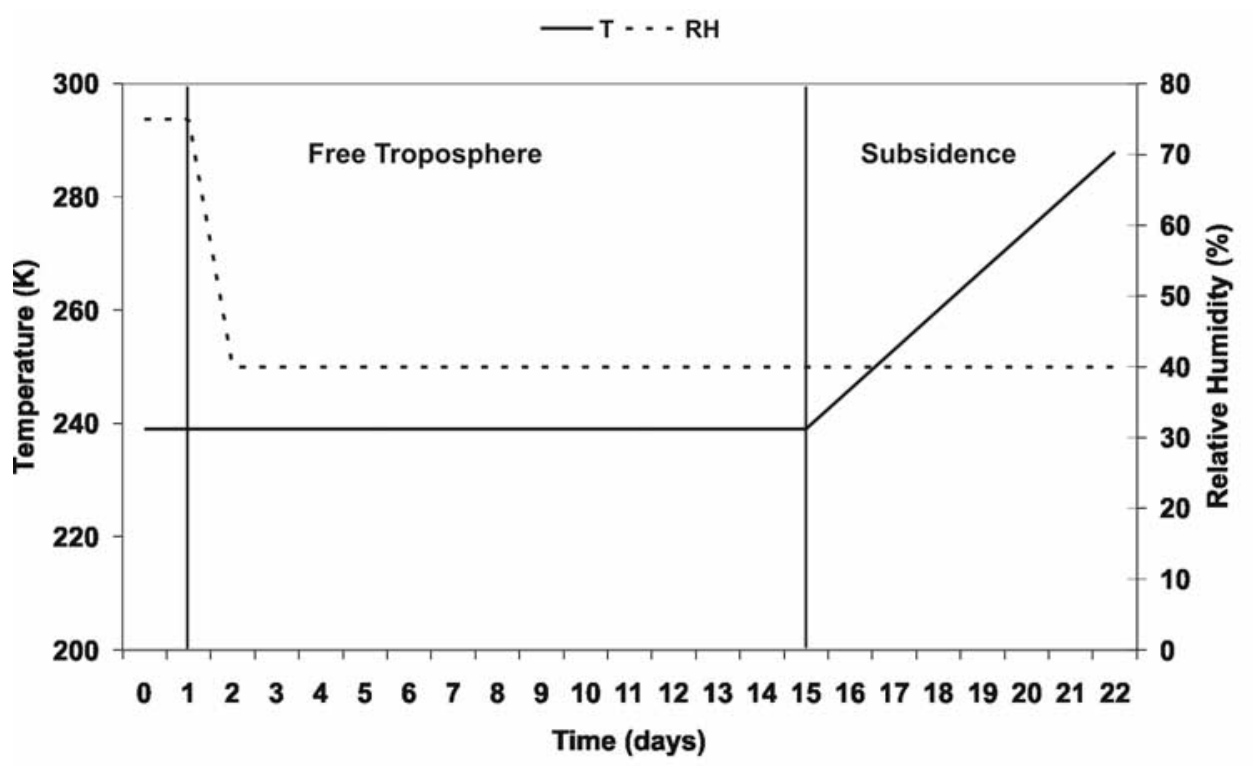

Figure 7. Relative humidity (dashed line) and temperature (solid line) evolution during the transport simulation in the free troposphere.

sphere (FT) aerosol dynamics and nucleation play a role. Therefore M7 was tested running a case of transport of a clean air mass in the FT and the results are compared to measurements collected during a number of aircraft experiments [Clarke et al., 1998; Clarke and Kapustin, 2002]. The purpose of this qualitative comparison is to investigate the ability of the model to predict the correct order of magnitude of number concentrations and size distributions. During the measurements a substantial increase of the particle number concentrations was observed near clouds. Ultrafine particle numbers (particles with diameter between $3 \mathrm{~nm}$ and $10 \mathrm{~nm}$ ) were between 1000 and $10000\left(\mathrm{~cm}^{-3}\right)$ and the small size indicates that they were new nuclei. The production of new particles was associated with enhanced concentrations of water vapor and sulfuric acid and nucleation is favored when the temperature is cold and existing aerosol surface is very low. The new particles formed aloft in cloud outflow regions may provide a source of particles for the marine boundary layer (MBL) through subsidence [Raes, 1995]. This was evident also during the experiments when a monomodal distribution of volatile particles was observed in subsiding air.

[45] The simulation with M7 of the FT transport starts close to the cloud outflow (Figure 7), where the relative humidity is set to $75 \%$, temperature to $239 \mathrm{~K}$, using the measurements of Clarke et al. [1998]. No information is available on $\mathrm{SO}_{2}$ concentration to initialize the model, therefore a series of simulations were made using initial concentrations of $0.01,0.05$ and $0.1 \mathrm{ppb}$. $\mathrm{OH}$ has a diurnal cycle with an average concentration of $2 \times 10^{6}$ molec. $\mathrm{cm}^{-3}$. The nucleation scheme used for the simulation is from Vehkamaki et al. [2002]. The initial time of simulation is 6:00 am. The air mass is assumed to travel in the free troposphere for 15 days: the meteorological parameters are set in the first day of the run to represent the area close of the cloud. For the next two weeks the air mass travels in the free troposphere [Pruppacher and Klett, 1997] outside clouds, and $\mathrm{T}$ and $\mathrm{RH}$ are set to $239 \mathrm{~K}$ and $40 \%$, respectively. After this, the air mass subsidizes in one week toward the marine boundary layer, and the temperature gradually increases to $287 \mathrm{~K}$.

[46] The time evolution of the total particle number concentration shows a burst of newly formed particles occurring in the late morning when photochemical processes have made $\mathrm{H}_{2} \mathrm{SO}_{4}$ available by sulfur dioxide oxidation (Figure 8a, lines). The peaks of the particle concentrations are higher and occur earlier with increasing $\mathrm{SO}_{2}$ concentrations, then the concentrations decline during the following 24 hours. With this range of initial conditions the maximum concentrations are between $3 \times 10^{5}$ and $1.2 \times 10^{6}\left(\mathrm{~cm}^{-3}\right)$ very close to the cloud outflow, and between $1 \times 10^{4}\left(\mathrm{~cm}^{-3}\right)$ after 24 hour simulation.

[47] For the first hours the particle size is very small, less than $5 \mathrm{~nm}$. In Figure 8a the part of the time series when particles have a diameter larger than $5 \mathrm{~nm}$ is plotted with symbols. The choice of $5 \mathrm{~nm}$ has been decided taking into account the cut off of the ultrafine condensation nuclei counters at $3 \mathrm{~nm}$ and the collection efficiency at that size.

[48] After 15 day simulation in the free troposphere the particle concentrations are no longer dependent on the initial $\mathrm{SO}_{2}$ value and are about 500 particles $\mathrm{cm}^{-3}$ (Figure $8 \mathrm{~b}$ ). Coagulation is the main process determining numbers and size.

[49] The size distributions predicted by M7 and reported in Figure 9a are monomodal with peaks at 25-30 nm for $\mathrm{SO}_{2}=0.01 \mathrm{ppb}$, which compares well with the measurements of Clarke et al. [1998], and a bimodal structure of the size distribution slightly appears for $\mathrm{SO}_{2}=0.05 \mathrm{ppb}$ and is evident for $\mathrm{SO}_{2}=0.1 \mathrm{ppb}$ During the ACE1 experiments in fact measurements were taken at various heights collecting information on size distributions, particle number concentrations as well as relative humidity and $\mathrm{H}_{2} \mathrm{SO}_{4}$ concentrations in the free troposphere down to the inversion over 


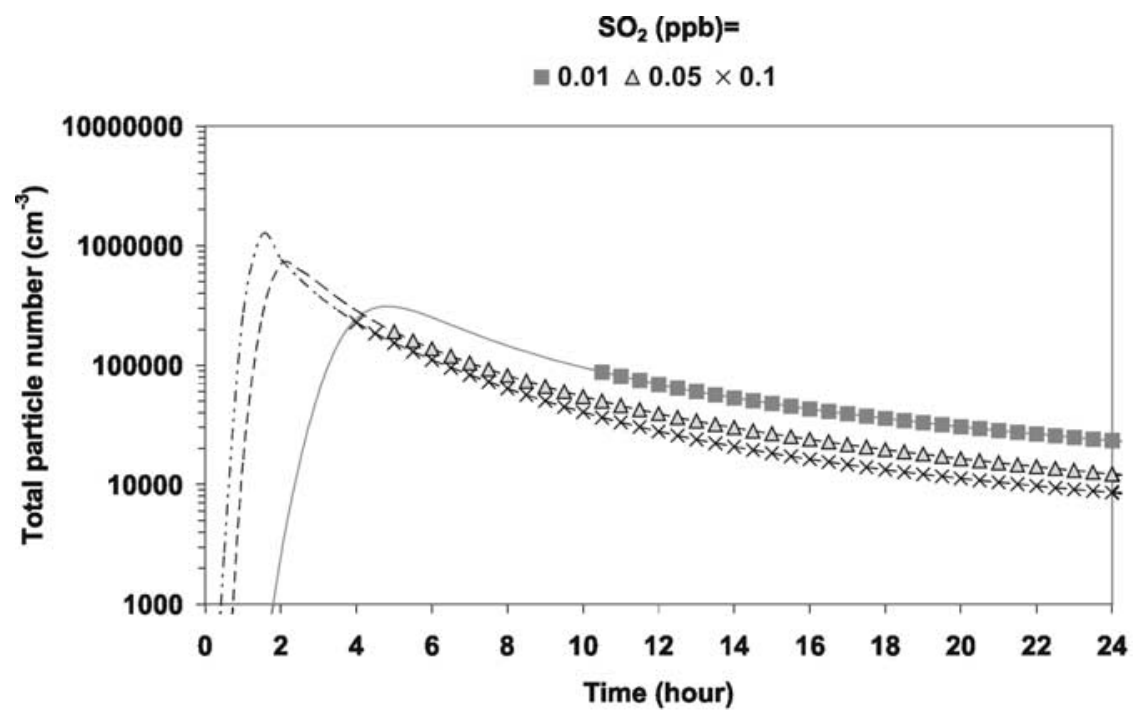

a)

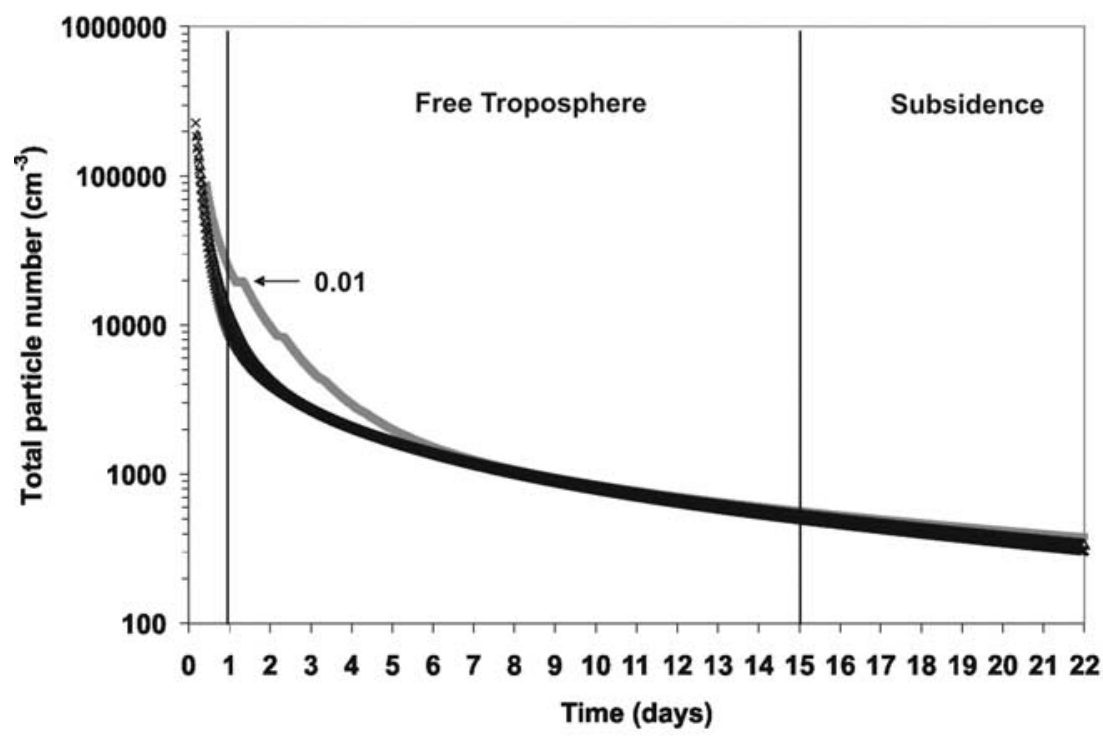

b)

Figure 8. Time evolution of total particle number calculated with $\mathrm{M} 7$ for different $\mathrm{SO}_{2}$ initial concentration: (a) zoom on the first day, close to the cloud outflow and (b) 22 day transport. Symbols are used to underline particles which have a diameter larger than $5 \mathrm{~nm}$.

the marine boundary layer. The study revealed the presence of an Aitken mode near $0.035 \mu \mathrm{m}$ at similar concentrations at altitude from 4210 to $2740 \mathrm{~m}$. In the last week the air mass subsidence is simulated and the particle numbers is reduced to $300-350$ particles $\mathrm{cm}^{-3}$ (Figure 9b).

[50] A similar case was run with AERO3 and presented by Raes et al. [2000] as a "clean case." M7 has been initialized with the particle concentrations present at the beginning of the free tropospheric transport for the AERO3 run and $\mathrm{SO}_{2}$ was $0.05 \mathrm{ppb}$. At the end of the FT transport AERO3 predicted a monomodal distribution peaking at a dry diameter of $20 \mathrm{~nm}$.

\section{Conclusions}

[51] The M7 model has been developed for applications as general aerosol microphysics module for regional and global aerosol models. It represents the predominant aerosol types at the global scale: sulfate, sea salt, dust, black carbon and primary organic carbon. Nucleation of sulfuric acidwater droplets, condensation of sulfuric acid on the particles, coagulation and water uptake are included. The aerosol population is composed by an external mixture of insoluble and internally mixed populations.

[52] Wilson et al. [2001] already tested the part of the M7 aerosol dynamics dealing with coagulation between soluble particles and condensation of $\mathrm{H}_{2} \mathrm{SO}_{4}$ on soluble particles. M7 describes dynamically the evolution of the size distributions of the components and in the paper the evaluation of model is done using the system sulphate-black carbon. Internally mixed aerosols are produced not only through condensation with sulfuric acid on insoluble particles, but also through coagulation between soluble and insoluble particles, and the mixing processes are tested comparing 


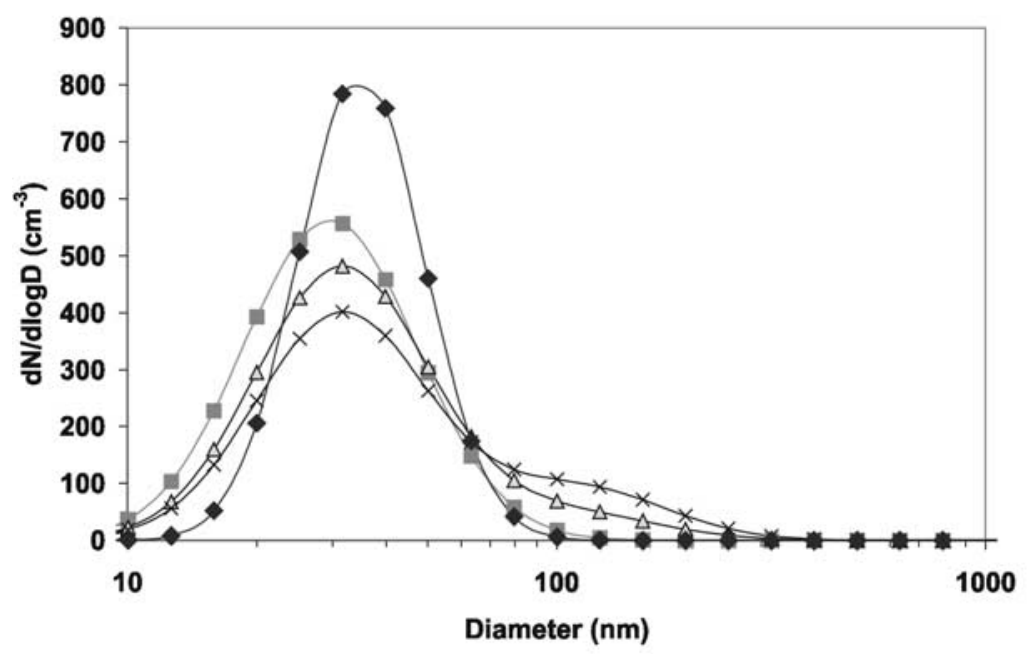

$\mathrm{SO}_{2}(\mathrm{ppb})$

0.01

$\triangle 0.05$

$* 0.1$

al. (1998)

a)

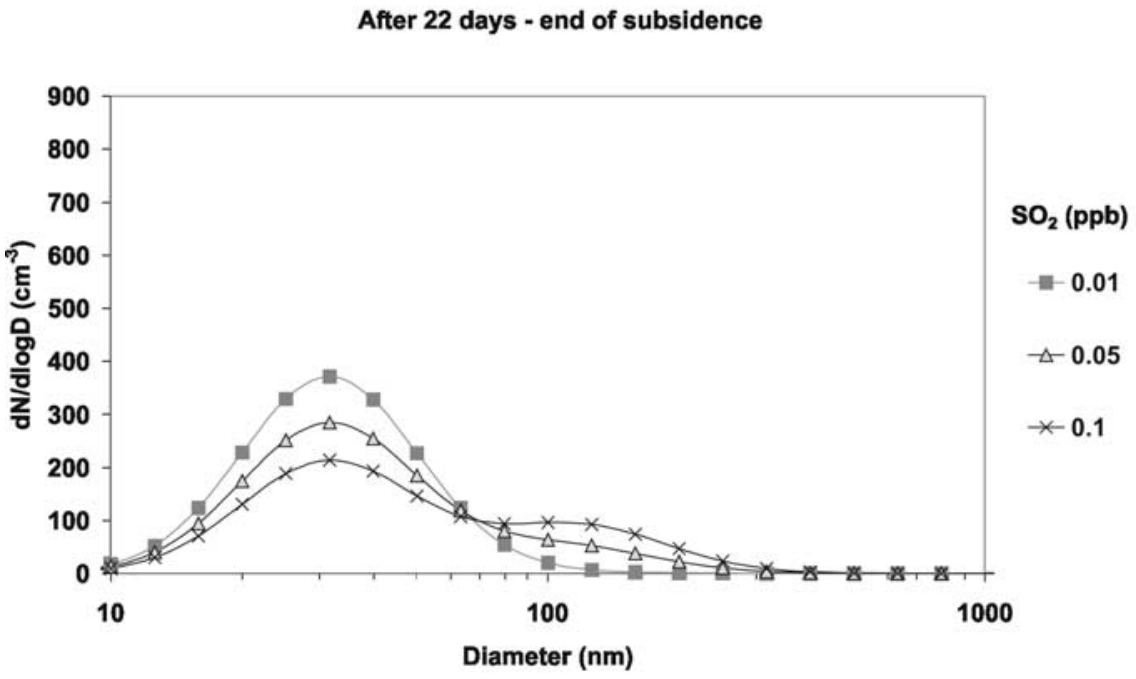

b)

Figure 9. Results of M7 application to the FT case $\left(\mathrm{cm}^{-3}\right.$ at STP conditions: $\left.15^{\circ} \mathrm{C}, 1013 \mathrm{hPa}\right)(\mathrm{a})$ after 15 days and (b) after 22 days. Size distributions for different $\mathrm{SO}_{2}$ initial concentrations and data are from Clarke et al. [1998].

M7 results to the sectional model AERO3 for mixing by coagulation and condensation and to an analytical solution for coagulation. M7 produces mixed particles more slowly than the other models when only coagulation is considered. However when condensation of sulfuric acid is included the transfer becomes faster.

[53] Unfortunately, data sets to fully evaluate the model performance are not available. Bearing in mind that in the free troposphere (FT) aerosol dynamics and nucleation play a role some runs were made in FT conditions and the results compared to aircraft measurements. Both size distributions and number concentrations from the application of M7 with initial range of $\mathrm{SO}_{2}$ values between 0.001 to $0.1 \mathrm{ppb}$ are in good agreement with the measurements.

[54] In spite of a restricted set of tests made on M7 the aerosol dynamics included in the model has proved to be able to represent the physical processes that act on the particles: nucleation, coagulation and condensation and water uptake. M7 has already been implemented in the aerosol model of the ECHAM5 GCM. This permits the evaluation of critical processes such as nucleation in comparison to the available measurements on the global scale. Results and a detailed evaluation of the model performance for all the compounds will be presented in a forthcoming publication. The application to the ECHAM5 allows using the model for long-term transient climate studies. Further development of M7 is under way with the implementation of nitrogen species, gas-aerosol partitioning of semivolatile species and a secondary organic carbon parameterization.

[55] Acknowledgments. We thank Frank Raes and Hans Feichter for their valuable advice and support during the development of M7 and in reviewing the paper. Frank Dentener and Rita van Dingenen and both reviewers are acknowledged for their constructive suggestions for the paper. This work was undertaken as part of the EC Env. And Climate project EVK2-CT-2001-00098 PHOENICS. 


\section{References}

Ackermann, I. J., H. Hass, M. Memmesheimer, A. Ebel, F. S. Binkowski, and U. Shankar (1998), Modal aerosol dynamics model for Europe: Development and first applications, Atmos. Environ., 32, $2981-$ 2999.

Albrecht, B. A. (1989), Aerosols, cloud microphysics, and fractional cloudiness, Science, 245, 1227-1230.

Bates, T. S., B. J. Huebert, J. L. Gras, F. B. Griffiths, and P. Durkee (1998), International Global Atmospheric Chemistry (IGAC) Project First Aerosol Characterization Experiment (ACE 1): Overview, J. Geophys. Res., 103, 16,297-16,318.

Calvert, J. G., F. Su, J. W. Bottenheim, and O. P. Strausz (1978), Mechanism of the homogeneous oxidation of sulfur dioxide in the troposphere, Atmos. Environ., 12, 197-226.

Carslaw, K. S., S. L. Clegg, and P. Brimblecombe (1995), A thermodynamic model of the system $\mathrm{HCl}-\mathrm{HNO}_{3}-\mathrm{H}_{2} \mathrm{SO}_{4}-\mathrm{H}_{2} \mathrm{O}$, including solubilities of HBr, J. Phys. Chem., 99, 11,557-11,574.

Charlson, R. J. J., J. Langner, H. Rodhe, C. B. Leovy, and S. G. Warren (1991), Perturbation of the Northern Hemisphere radiation balance by backscattering from anthropogenic sulfate aerosols, Tellus, Ser. AB, 42, $154-163$

Clarke, A. D., and V. N. Kapustin (2002), A Pacific aerosol survey. Part I: A decade of data on particle production, transport, evolution, and mixing in the troposphere, J. Atmos. Sci., 59, 363-382.

Clarke, A. D., J. L. Varner, F. Eisele, R. L. Mauldin, D. Tanner, and M. Litchy (1998), Particle production in the remote marine atmosphere: Cloud outflow and subsidence during ACE 1, J. Geophys. Res., 103 $16,397-16,409$

Clegg, S. L., P. Brimblecombe, and A. S. Wexler (1998a), A thermodynamic model of the system $\mathrm{H}-\mathrm{NH}_{4}-\mathrm{SO}_{4}-\mathrm{NO}_{3}-\mathrm{H}_{2} \mathrm{O}$ at tropospheric temperatures, J. Phys. Chem. A, 102, 2137-2154.

Clegg, S. L., P. Brimblecombe, and A. S. Wexler (1998b), A thermodynamic model of the system $\mathrm{H}-\mathrm{NH}_{4}-\mathrm{Na}-\mathrm{SO}_{4}-\mathrm{NO}_{3}-\mathrm{Cl}-\mathrm{H}_{2} \mathrm{O}$ at $298.15 \mathrm{~K}$, J. Phys. Chem. A, 102, 2155-2171.

Cooke, W. F., and J. J. N. Wilson (1996), A global black carbon aerosol model, J. Geophys. Res., 101, 19,395-19,409.

Decesari, S., M. C. Facchini, M. Mircea, F. Cavalli, and S. Fuzzi (2003), Solubility properties of surfactants in atmospheric aerosol and cloud/fog water samples, J. Geophys. Res., 108(D21), 4685, doi:10.1029/ 2003JD003566.

Eck, T. F., B. N. Holben, I. Slutsker, and A. Setzer (1998), Measurements of irradiance attenuation and estimation of the aerosol single scattering albedo for biomass burning in Amazonia, J. Geophys. Res., 103 31,865-31,878.

Eisele, F. L., and D. J. Tanner (1993), Measurement of the gas phase concentration of $\mathrm{H}_{2} \mathrm{SO}_{4}$ and methane sulfonic acid and estimates of $\mathrm{H}_{2} \mathrm{SO}_{4}$ production and loss in the atmosphere, J. Geophys. Res., 98, 9001-9010

Fassi-Fihri, A., K. Suhre, and R. Rosset (1997), Internal and external mixing in atmospheric aerosols by coagulation: Impact on the optical and hygroscopic properties of the sulphate-soot system, Atmos. Environ., 3l(10), 1393-1402.

Fuchs, N. A. (1964), The Mechanics of Aerosols, Pergamon, New York.

Gong, S. L., et al. (2003), Canadian Aerosol Module: A size-segregated simulation of atmospheric aerosol processes for climate and air quality models: 1. Module development, J. Geophys. Res., 108(D1), 4007, doi:10.1029/2001JD002002.

Hansson, H.-C., A. Wiedensohler, M. J. Rood, and D. S. Covert (1990), Experimental determination of the hygroscopic properties of organically coated aerosol particles, J. Aerosol Sci., 2, S241-S244.

Haywood, J. M., and K. P. Shine (1995), The effect of anthropogenic sulfate and soot aerosol on the clear sky planetary radiation budget, Geophys. Res. Lett., 22(5), 603-606.

Intergovernmental Panel on Climate Change (IPCC) (2001), Climate Change 2001: Third Assessment Report of the Intergovernmental Panel on Climate Change, edited by J. T. Houghton et al., 881 pp., Cambridge Univ. Press, New York.

Jacobson, M. Z. (2001), Global direct radiative forcing due to molticomponent anthropogenic and natural aerosols, J. Geophys. Res., 106, $1551-$ 1568 .

Jacobson, M. Z., A. Tabazadeh, and R. P. Turco (1996), Simulating equilibrium within aerosols and nonequilibrium between gases and aerosols, J. Geophys. Res., 101, 9079-9091.

Jefferson, A., F. L. Eisele, P. J. Ziemann, R. J. Weber, J. J. Marti, and P. H. McMurry (1997), Measurements of the $\mathrm{H}_{2} \mathrm{SO}_{4}$ mass accommodation coefficient onto polydisperse aerosol, J. Geophys. Res., 102, 19,02119,028 .

Kulmala, M., A. Laaksonen, and L. Pirjola (1998), Parameterizations for sulfuric acid/water nucleation rates, J. Geophys. Res., 103(D7), 83018307
O’Dowd, C. D., M. H. Smith, I. E. Consterdine, and J. A. Lowe (1997), Marine aerosol, sea-salt, and the marine sulphur cycle: A short review, Atmos. Environ., 31, 73-80.

Pirjola, L., S. Tsyro, L. Tarrason, and M. Kulmala (2003), A monodisperse aerosol dynamic module, a promising candidate for use in long-range transport models: Box model test, J. Geophys. Res., 108(D9), 4258, doi:10.1029/2002JD002867.

Pruppacher, H. R., and J. D. Klett (1997), Microphysics of Cloud and Precipitation, Kluwer Acad., Norwell, Mass.

Raes, F. (1995), Entrainment of free tropospheric aerosols as a regulating mechanism for cloud condensation nuclei in the remote marine boundary layer, J. Geophys. Res., 100, 2893-2903.

Raes, F., and R. Van Dingenen (1992), Simulations of condensation and cloud condensation nuclei in the remote marine boundary layer, J. Geophys. Res., 97, 12,901-12,912.

Raes, F., R. Van Dingenen, E. Vignati, J. Wilson, J.-P. Putaud, J. H. Seinfeld, and P. Adams (2000), Formation and cycling of aerosols in the global troposphere, Atmos. Environ., 34, 4215-4240.

Rodriguez, M. A., and D. Dabdub (2004), IMAGES-SCAPE2: A modeling study of size- and chemically resolved aerosol thermodynamics in a global chemical transport model, J. Geophys. Res., 109, D02203, doi:10.1029/2003JD003639

Roeckner, E., et al. (2003), The atmospheric general circulation model ECHAM 5. Part I: Model description, Rep. 349, Max Planck Inst. for Meteorol., Hamburg, Germany.

Rosenfeld, D. (2000), Suppression of rain and snow by urban and industrial air pollution, Science, 287, 1793-1796.

Russell, P. B., P. V. Hobbs, and L. L. Stowe (1999), Aerosol properties and radiative effects in the United States East Coast haze plume: An overview of the Tropospheric Aerosol Radiative Forcing Observational Experiment (TARFOX), J. Geophys. Res., 104, 2213-2222.

Satheesh, S. K., and V. Ramanathan (2000), Large differences in tropical aerosol forcing at the top of the atmosphere and Earth's surface, Nature, $405,60-63$

Schell, B. (2000), Die Behandlung sekundärer organischer Aerosole in einem komplexen Chemie-Transport-Modell, Ph.D. thesis, 135 pp., Univ. zu Köln., Cologne, Germany.

Shaw, M. A., and M. J. Rood (1990), Measurement of the crystallization humidities of ambient aerosol particles, Atmos. Environ. A, 24, 18371841 .

Smoluchovski, M. V. (1917), Versuch einer mathematischen Theorie der Koagulationkinetik kolloidaler Lösungen, Z. Phys. Chem., 92, 129-168.

Stokes, R. H., and R. A. Robinson (1966), Interactions in aqueous nonelectrolyte solutions. I. Solute-solvent equilibria, J. Phys. Chem., 70, $2126-2130$

Takemura, T., H. Okamoto, Y. Maruyama, A. Numaguti, A. Higurashi, and T. Nakajima (2000), Global three-dimensional simulation of aerosol optical thickness distribution of various origins, J. Geophys. Res., 105(D14), 17,853-17,874

Tegen, I., P. Hollrig, M. Chin, I. Fung, D. Jacob, and J. Penner (1997), Contribution of different aerosol species to the global aerosol extinction optical thickness: Estimates from model results, J. Geophys. Res., 102 , $23,895-23,915$.

Tervahattu, H., K. Hartonen, V.-M. Kerminen, K. Kupiainen, P. Aarnio, T. Koskentalo, A. F. Tuck, and V. Vaida (2002), New evidence of an organic layer on marine aerosols, J. Geophys. Res., 107(D7), 4053, doi:10.1029/2000JD000282.

Twomey, S. (1974), Pollution and the planetary albedo, Atmos. Environ., 8, $1251-1256$.

Twomey, S. (1977), Atmospheric Aerosols, Elsevier Sci., New York.

Van Dingenen, R., and F. Raes (1991), Determination of the condensation accommodation coefficient of $\mathrm{H}_{2} \mathrm{SO}_{4}$ on $\mathrm{H}_{2} \mathrm{SO}_{4}-\mathrm{H}_{2} \mathrm{O}$ aerosol, Aerosol Sci. Technol., 15, 93-106.

Vehkamaki, H., M. Kulmala, I. Napari, K. E. J. Lehtinen, C. Timmreck, M. Noppel, and A. Laaksonen (2002), An improved parameterization for sulfuric acid-water nucleation rates for tropospheric and stratospheric conditions, J. Geophys. Res., 107(D22), 4622, doi:10.1029/ 2002JD002184.

Vignati, E. (1999), Modelling interactions between aerosols and gaseous compounds in the polluted marine atmosphere, Rep. Risø-R-1163 (EN), 133 pp., Risø Natl. Lab., Univ. of Copenhagen, Copenhagen.

Virkkula, A., R. van Dingenen, F. Raes, and J. Hjorth (1999), Hygroscopic properties of aerosols formed by oxidation of limonene, $\alpha$-pinene, and ß-pinene, J. Geophys. Res., 104(D3), 3569-3579.

Whitby, E. R., and P. H. McMurry (1997), Modal aerosol dynamics modelling, Aerosol Sci. Technol., 27, 673-688.

Williams, M. M. R., and S. K. Loyalka (1991), Aerosol Science: Theory and Practice, Pergamon, New York.

Wilson, J., C. Cuvelier, and F. Raes (2001), A modeling study of global mixed aerosol fields, J. Geophys. Res., 106, 34,081-34,108. 
Wright, D. L., P. S. Kasibhatla, R. McGraw, and S. E. Schwartz (2001), Description and evaluation of a six-moment aerosol microphysical module for use in atmospheric chemical transport models, J. Geophys. Res., 106, 20,275-20,291.

Zdanovskii, A. B. (1948), New methods for calculating solubilities of electrolytes in multicomponent systems, Zhur. Fiz. Khim., 22, 14751485

Zeleznik, F. J. (1991), Thermodynamic properties of the aqueous sulfuric acid system to $350 \mathrm{~K}$, J. Phys. Chem. Ref. Data, 20, $1157-$ 1200

Zhang, Y., C. Seigneur, J. H. Seinfeld, M. Z. Jacobson, and F. S Binkowsky (1999), Simulation of aerosol dynamics: A comparative review of algorithms used in air quality models, Aerosol Sci. Technol., $31,487-514$

Zhang, Y., R. C. Easter, S. J. Ghan, and H. Abdul-Razzak (2002), Impact of aerosol size representation on modeling aerosol-cloud interactions, J. Geophys. Res., 107(D21), 4558, doi:10.1029/2001JD001549.

P. Stier, Max Planck Institute for Meteorology, Bundesstrasse 53, 20146 Hamburg, Germany.

E. Vignati and J. Wilson, Institute for Environment and Sustainability, Joint Research Centre, European Commission, TP 280, Via E. Fermi, 21020 Ispra (VA), Italy. (elisabetta.vignati@jrc.it) 